\title{
Differential transcript profiling through cDNA-AFLP showed complexity of rutin biosynthesis and accumulation in seeds of a nutraceutical food crop (Fagopyrum spp.)
}

Nidhi Gupta, Pradeep Kumar Naik and Rajinder Singh Chauhan ${ }^{*}$

\begin{abstract}
Background: Buckwheat, consisting of two cultivated species Fagopyrum tataricum and F. esculentum, is the richest source of flavonoid rutin. Vegetative tissues of both the Fagopyrum species contain almost similar amount of rutin; however, rutin content in seed of $F$. tataricum are $\sim 50$ folds of that in seed of $F$. esculentum. In order to understand the molecular basis of high rutin content in F. tataricum, differential transcript profiling through CDNA-AFLP has been utilized to decipher what genetic factors in addition to flavonoid structural genes contribute to high rutin content of F. tataricum compared to F. esculentum.

Results: Differential transcript profiling through CDNA-AFLP in seed maturing stages (inflorescence to seed maturation) with 32 primer combinations generated total of 509 transcript fragments (TDFs). 167 TDFs were then eluted, cloned and sequenced from F. tataricum and F. esculentum. Categorization of TDFs on the basis of their presence/absence (qualitative variation) or differences in the amount of expression (quantitative variation) between both the Fagopyrum species showed that majority of variants are quantitative (64\%). The TDFs represented genes controlling different biological processes such as basic and secondary metabolism (33\%), regulation (18\%), signal transduction (14\%), transportation (13\%), cellular organization (10\%), and photosynthesis \& energy (4\%). Most of the TDFs except belonging to cellular metabolism showed relatively higher transcript abundance in $F$. tataricum over $F$. esculentum. Quantitative RT-PCR analysis of nine TDFs representing genes involved in regulation, metabolism, signaling and transport of secondary metabolites showed that all the tested nine TDFs (Ubiquitin protein ligase, ABC transporter, sugar transporter) except MYB 118 showed significantly higher expression in early seed formation stage (S7) of $F$. tataricum compared to F. esculentum. GRT-PCR results were found to be consistent with the CDNA-AFLP results.

Conclusions: The present study concludes that in addition to structural genes, other classes of genes such as regulators, modifiers and transporters are also important in biosynthesis and accumulation of flavonoid content in plants. CDNA-AFLP technology was successfully utilized to capture genes that are contributing to differences in rutin content in seed maturing stages of Fagopyrum species. Increased transcript abundance of TDFs during transition from flowers to seed maturation suggests their involvement not only in the higher rutin content of $F$. tataricum over $F$. esculentum but also in nutritional superiority of the former.
\end{abstract}

Keywords: Rutin, CDNA-AFLP, Transcript derived fragments, qRT-PCR

\footnotetext{
* Correspondence: rajinder.chauhan@juit.ac.in

Department of Biotechnology \& Bioinformatics, Jaypee University of

Information Technology, Waknaghat, Solan 173234 H.P, India
} 


\section{Background}

Buckwheat; Fagopyrum spp. is a pseudo-cereal multipurpose food crop used for both grains and greens with several medicinal and nutritional properties [1-3]. Genus Fagopyrum belongs to Polygonaceae and has 20 known species which mainly occur in the highlands of Euro-Asia [4-6]. Out of these, two cultivated species, Fagopyrum esculentum (common buckwheat) and F. tataricum (tartary buckwheat) are of high economic importance due to multiple uses such as a substitute for cereals in human consumption, as a vegetable crop, honey crop, and of ethno-botanical importance [7]. Significantly higher contents of flavonoids such as rutin and other polyphenols also add significance to the dietary value of buckwheat [8].

In tartary buckwheat, fagopyritols; mono-, di- and trigalactosyl derivatives of D-chiro-inositol account for $40 \%$ of total soluble carbohydrates compared to $21 \%$ in common buckwheat thus, helps in the treatment of diabetes [9]. Total flavonoids are relatively higher in tartary buckwheat $(40 \mathrm{mg} / \mathrm{g}$ ) compared to common buckwheat $(10 \mathrm{mg} / \mathrm{g})$ of which rutin is the major component [7]. Rutin a major flavonoid of medicinal value is found in higher quantities in buckwheat thus, considered as a major dietary source of rutin $[1,2,8]$. Tartary buckwheat seeds contain more rutin (about 0.8 to $1.7 \%$ DW) compared to common buckwheat seeds $(0.01 \% \mathrm{DW})$ [8]. Due to the presence of proteins with high biological value (90\%) and flavonoids with higher concentration in tartary buckwheat compared to common buckwheat, the former is considered an excellent food material with a potential for preventive nutrition [10]. But tartary buckwheat has a tightly adhering hull that makes it difficult to dehull and contains a bitter component that affects its palatability [1]. However, Rice-tartary is a type of tartary buckwheat ( $F$. tataricum) with a non-adhering hull property, and can be a potential nutraceutical food source [11].

Molecular basis of nutritional superiority, particularly higher rutin content in $F$. tataricum compared to $F$. esculentum, is not fully understood. De-novo sequencing was used to understand molecular basis of morphological variations in the flowers of Fagopyrum species [12]. In addition, it has been observed that the flavonoid biosynthesis genes in $F$. esculentum were highly expressed in lower parts of plants than upper parts suggesting that flavonoids may be transported within a plant [13]. Anthocyanin content of $F$. tataricum has been correlated with the differential expression of flavonoid biosynthesis genes [14]. Comparative analysis of rutin content in different seed maturation stages of rice-tartary and tartary buckwheat compared to common buckwheat showed that all the postflowering stages, S6, S7, S8 and S9 of rice-tartary contained $1.5,31,8$, and $43 \mathrm{x}$ higher rutin content compared to common buckwheat, respectively [15]. Stages S6, S7, and S8 of rice-tartary contained higher rutin content even compared to tartary buckwheat; Figures 1 \& 2. Relatively higher expression of flavonoid pathway genes, phenylalanine ammonia lyase; PAL 4.3.1.24, chalcone synthase; $\mathrm{CHS}$ 2.3.1.74, chalcone isomerase; $\mathrm{CHI}$ 5.5.1.6 and flavonol synthase; FLS 1.14.11.23 were suggested to be responsible for higher rutin content in rice-tartary compared to common buckwheat [15]. However, increase in the expression of PAL, CHS, CHI and FLS genes did not occur concomitant to an increase in rutin content. Therefore, identification of additional genes, if any, was carried out to investigate molecular basis of high rutin content in flowering and post-flowering stages of $F$. tataricum compared to F. esculentum.

Flavonoid content in a particular tissue and developmental stage is largely influenced by different classes of regulatory genes, transporters, modifiers etc. in addition to structural genes of the flavonoid biosynthetic pathway [16-18]. Lack of whole genome sequence and nonavailability of ESTs from developing seeds of Fagopyrum spp. prompted us to utilize cDNA-AFLP to decipher what genetic factors contribute to nutritional superiority of rice-tartary buckwheat compared to common buckwheat. Present study reports several differentially expressed transcript fragments representing genes involved in basic and secondary metabolism, transcription factors, transporters, etc., which were validated through qRT-PCR to associate their contribution in nutritional superiority of rice-tartary over common buckwheat.

\section{Results}

\section{Identification and analysis of differentially expressed} transcripts (TDFs)

cDNA-AFLP analysis on RNA samples from flower to mature seed stages of rice-tartary and common buckwheat with 32 primer pair combinations resulted in the identification of 42 clear and unambiguous fragments (TDFs). The TDFs ranged in sizes from $150-750 \mathrm{bp}$ representing a total of 2,584 TDFs.

A total of 167 differential TDFs based on presence/ absence or differences in intensity were eluted from the gels, re-amplified and sequenced; Figure 3. DNA sequence of each TDF was assigned a putative biological function by checking against the Gene Bank database (BLASTN/BLASTX) as well as the TAIR database; Figure 4. TDFs represented genes controlling different biological processes such as general and secondary metabolism (33\%), regulation (18\%), signal transduction (14\%), transportation (13\%), cellular organization (10\%), transposable elements (7\%), photosynthesis $(4 \%)$ and defense \& response to stimuli (1\%); Additional file 1: Table S1, Figure 4. 


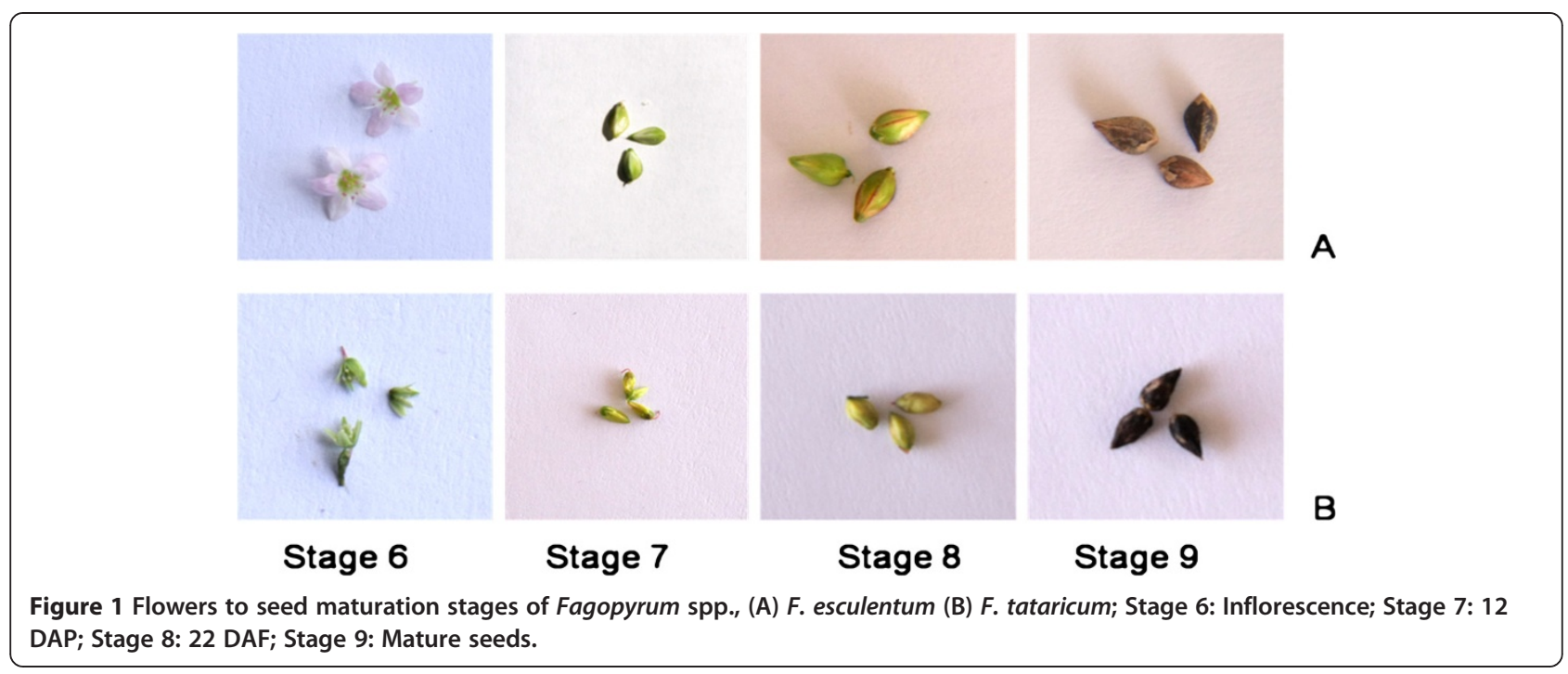

TDFs representing genes encoding alanine glyoxlate, methionine sulfoxide, fatty acid desaturase, KAS III, sucrose 6 phosphatase, ubiquitin protein ligases etc. were implicated in the biosynthesis of proteins \& amino acids (12\%), fatty acids (7\%) and carbohydrates (6\%). Similarly, $8 \%$ of TDFs corresponded to genes for key enzymes involved in secondary metabolism, including the flavonoid and anthocyanin biosynthesis. TDFs (10\%) involved in cellular function included genes coding for pectin acyltransferases, proline rich extensins, glycine rich proteins, and arabinogalactan etc. TDFs corresponding to transporters (13\%) included $\mathrm{ABC}$ transporters, auxin hydrogen symporter, sugar transporters, zinc and potassium transporters. Genes involved in signal transduction (14\%) and regulation (18\%), including $\mathrm{Zn}$ finger binding proteins, Leucine rich repeats calmodulin binding protein, protein kinases and transcription factors belongs to MYB and WRKY classes were also detected.

TDFs representing differentially expressed genes were classified into different categories on the basis of their presence/absence (qualitative variation) or differences in amount of expression (quantitative variation) between both the Fagopyrum species so as to infer whether TDFs belonging to a particular biological functional class are preferentially expressed in a particular Fagopyrum species; Figure 5A \& B. TDFs representing genes involved in carbohydrate metabolism and signal transduction were relatively higher in number in $F$. esculentum, whereas TDFs representing genes involved in secondary metabolism, amino acid \& protein metabolism, energy and photosynthesis were more in rice-tartary buckwheat; Figure 5A. Most of the TDFs belonged to genes for

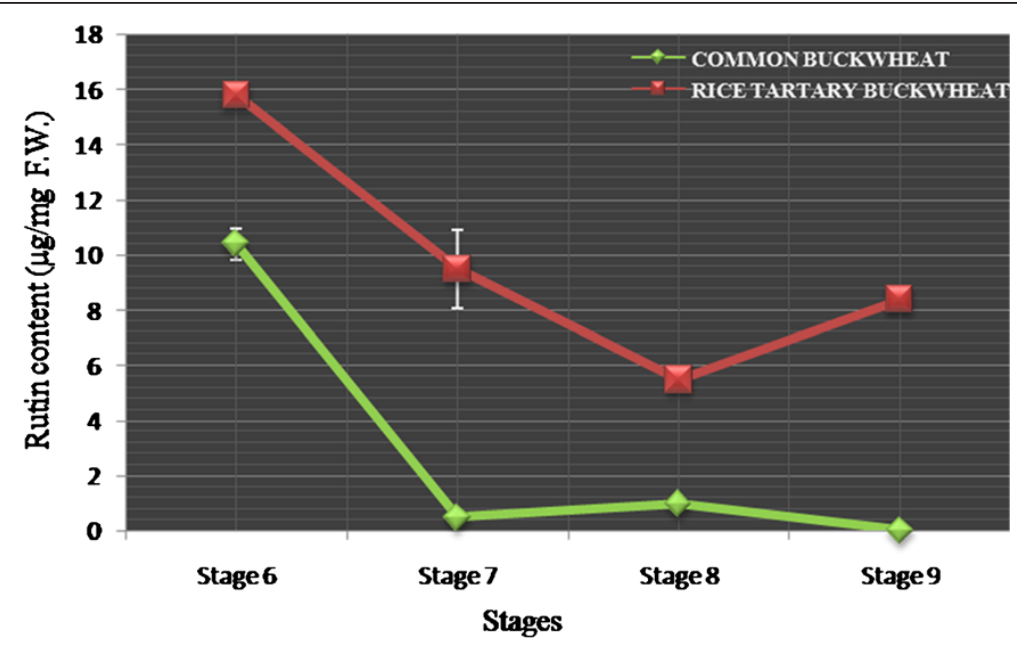

Figure 2 Rutin content variation: rutin content variation during seed developmental stages of Fagopyrum spp, Rice-tartary Buckwheat (IC-329457), Common Buckwheat (IC-5408858). 


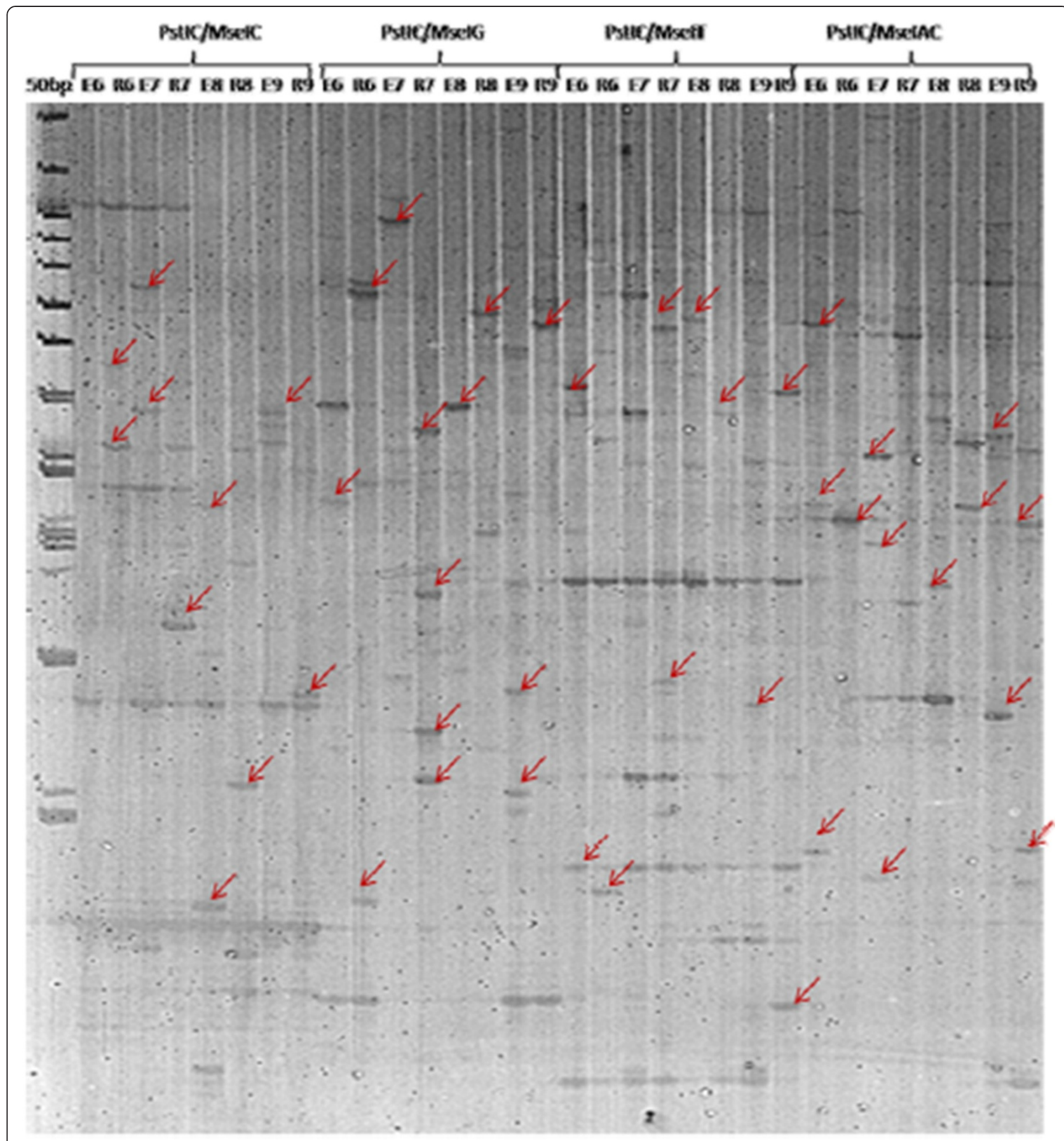

Figure 3 cDNA-AFLP patterns: Rice-tartary (R) vs Common Buckwheat (E) in seed maturation stages (6, 7, 8, and 9).

transporters, transcriptional regulation, secondary metabolism, photosynthesis \& energy, carbohydrate, protein and amino acid metabolism and showed relatively increased transcript abundance in rice-tartary compared to common buckwheat; Figure 5B. Whereas, only TDFs for cellular metabolism showed relatively more transcript abundance in common buckwheat compared to rice-tartary buckwheat.
TDFs representing genes involved in transport of metabolites (ABC and sugar transporters, auxin hydrogen symporter), regulation of biosynthesis (MYB TF, Zn finger protein), metabolism of metabolites (ubiquitin protein ligases, extensin protein), signal transduction (calmodulin binding protein) and energy transfer (ATP CF0 subunit) were chosen for quantitative RT-PCR analysis in different seed maturing stages of both the Fagopyrum species. 


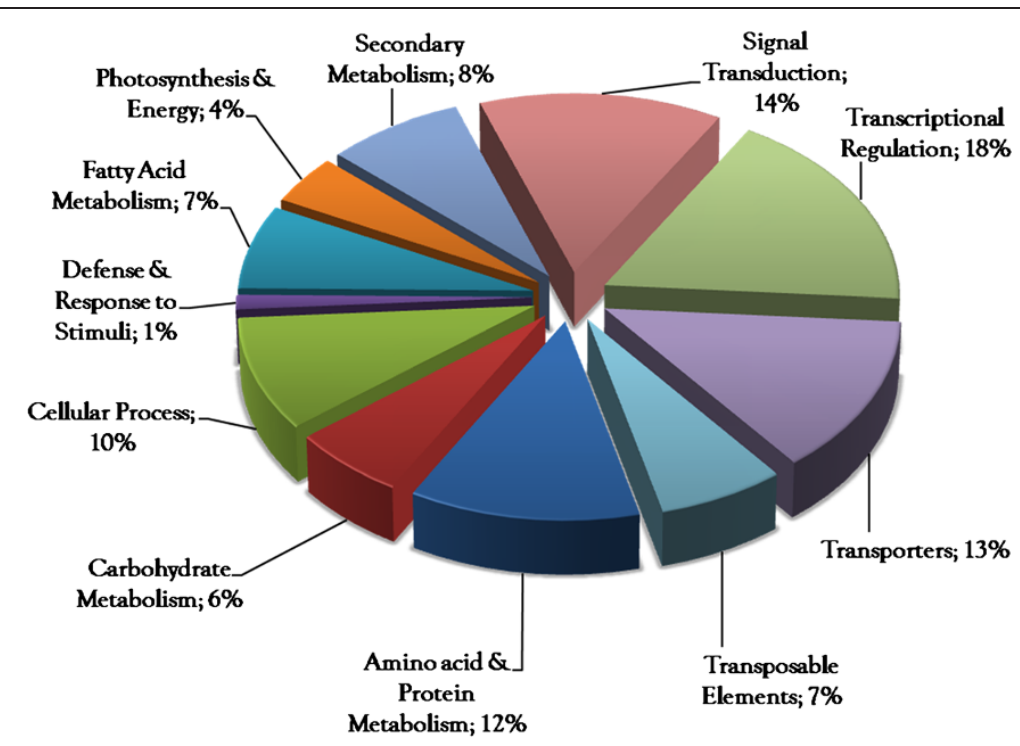

Figure 4 Functional classification of transcript derived fragments: Transcript derived fragments categorized into different categories.

Transcript quantification of selected TDFs in flower to seed maturation stages of Fagopyrum spp

Four TDFs representing genes for Ubiquitin protein ligase (JN982742), ABC transporter (JN982732), sugar transporter (JN982735) and MYB118 (JN982734) showed significantly increased transcript abundance in flowers (S6) of ricetartary compared to common buckwheat with 2.86, 4.71, 7.36 and 11.42 folds expression, respectively; Figure 6A. Relatively higher abundance was observed for TDFs from genes for $\mathrm{ABC}$ transporter, sugar transporter, $\mathrm{Ub}$ protein ligase and Zn finger binding protein (JN982723) in immature seed stage (S7) of rice-tartary buckwheat with 95.38,
$49.25,18.92,17.29$ folds, respectively over common buckwheat; Figure 6B. On the other hand, 5 TDFs from genes encoding $\mathrm{Zn}$ finger binding protein, ATP CF0 subunit (JN982718), calmodulin binding protein, extensin (JQ003863) and auxin efflux (JN982731) showed relatively increased transcript abundance in the immature seeds (S8) of common buckwheat compared to rice-tartary buckwheat with 22.22, 11.94, 4.04, 3.89, and 1.64 folds higher abundance respectively. Two TDFs for ABC transporter (2.38 folds) and MYB118 (1.61 folds) showed relatively increased abundance in S8 of rice-tartary in comparison to common buckwheat; Figure 6C. In mature seeds (S9),

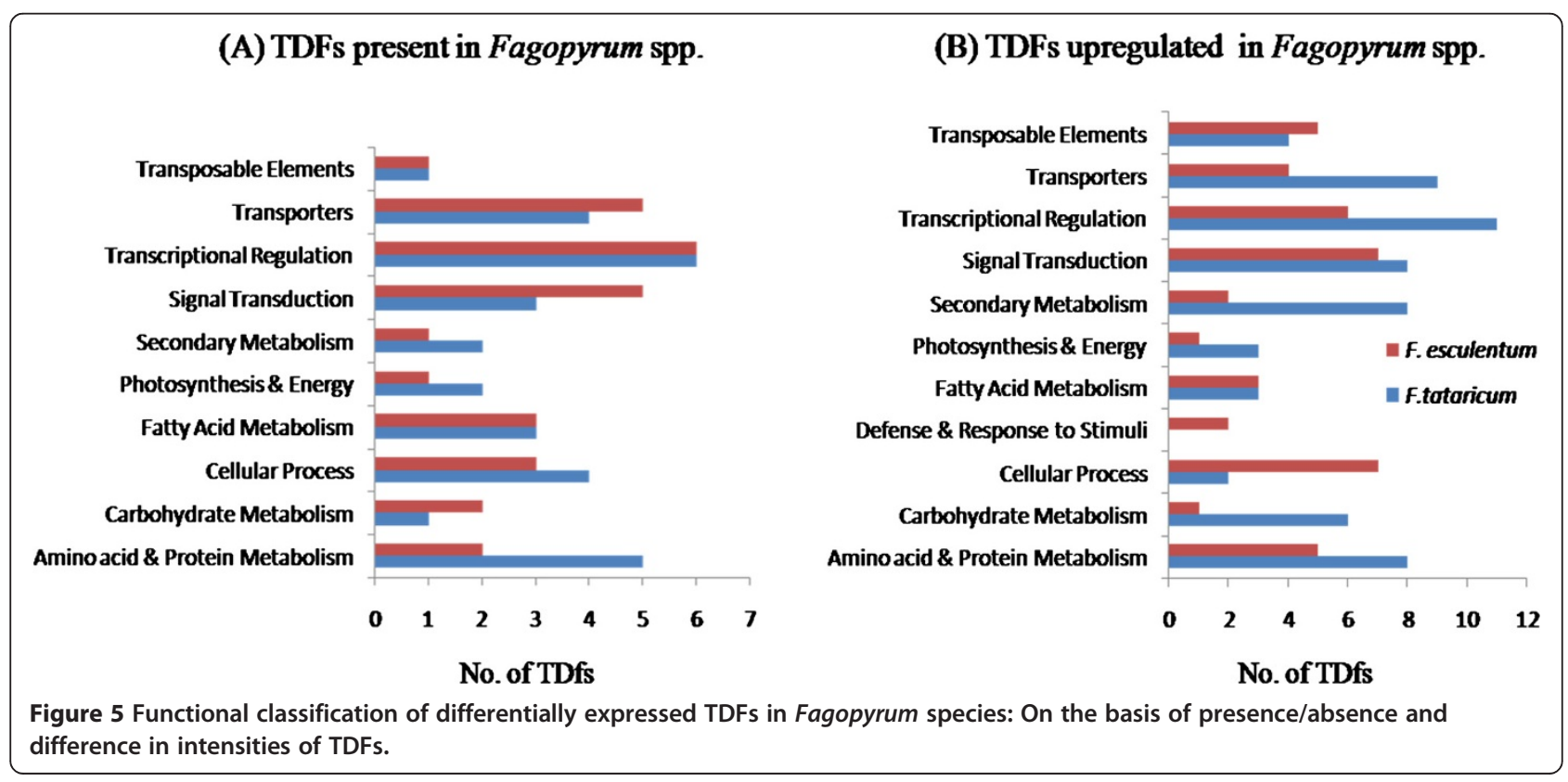




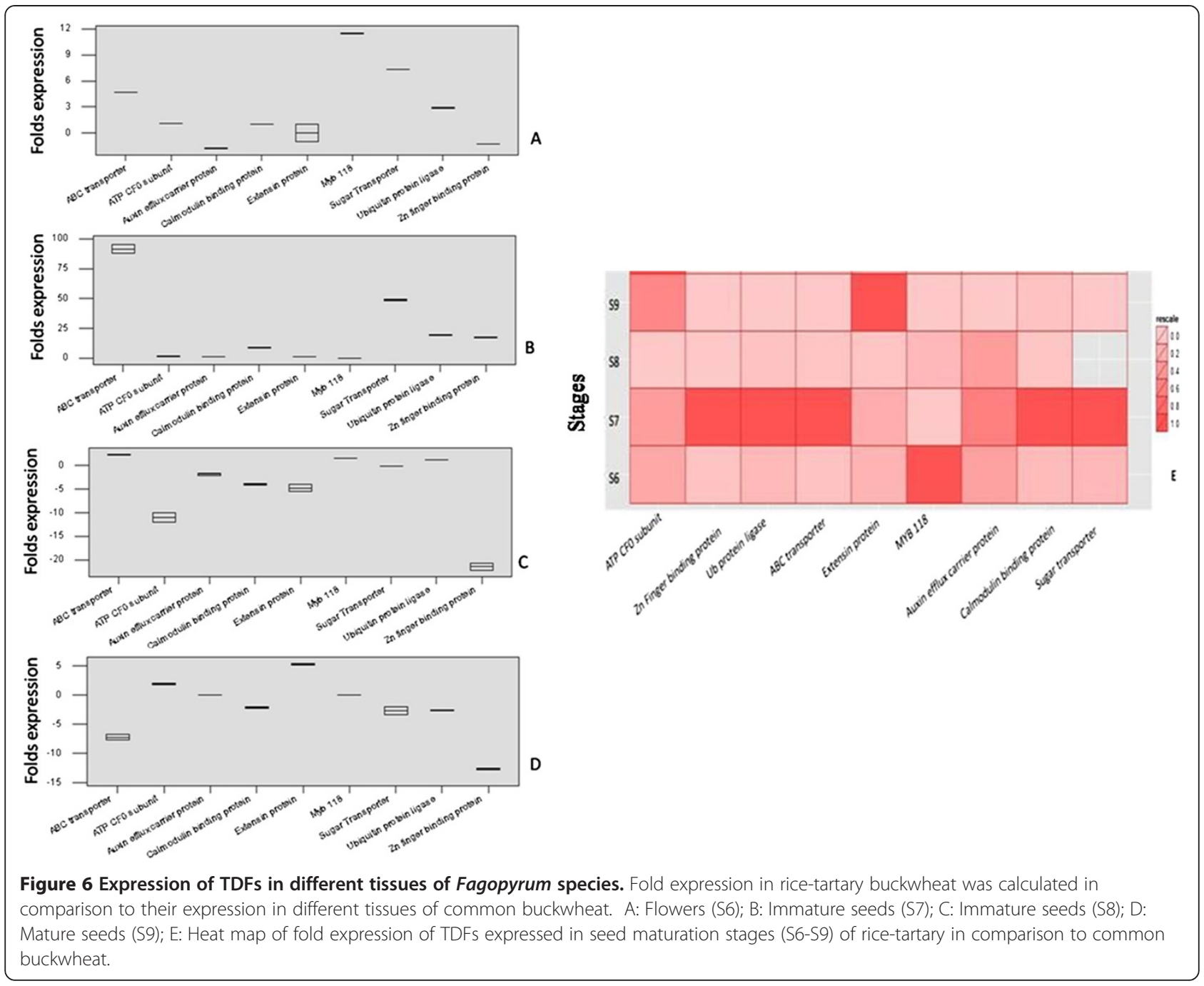

the expression of TDFs Zn finger binding protein (12.54 folds), $\mathrm{ABC}$ transporter (6.78 folds), Ub protein ligase (2.54 folds), calmodulin binding protein ( 2.32 folds), and sugar transporter ( 2.07 folds) was found to be higher in common compared to rice-tartary buckwheat. Whereas, extensin and ATP CF0 subunit showed relatively higher expression in rice-tartary over common buckwheat in mature seeds (S9) with 5.42 and 2.09 folds, respectively; Figure 6D. No transcript was detected for MYB 118 and auxin efflux carrier protein in mature seeds of rice-tartary buckwheat. Therefore, the transcripts of ubiquitin protein ligases, $\mathrm{ABC}$ transporter and sugar transporter showed relatively higher expression in three stages of seed development, including flowers and immature seeds of ricetartary compared to common buckwheat.

\section{Discussion}

Understanding types and number of genes differentially expressed during seed maturation would help in discerning molecular mechanisms contributing to nutritional superiority, including high rutin content in the seeds of $F$. tataricum (rice-tartary buckwheat) over F. esculentum [16]. De-novo sequencing of transcripts from flowers of Fagopyrum species (F. tataricum and F. esculentum) had shown that genes contributing to different biological processes are contributing to variations in the morphology of flowers in Fagopyrum species [12]. Accumulation of higher amounts of rutin during postflowering stages of $F$. tataricum (rice-tartary buckwheat) over F. esculentum has also been observed [15]. Overall nutritional superiority of F. tataricum over other Fagopyrum spp has been found in the mature seeds as well as during seed maturation stages. For example, increase in fagopyritols content was shown from immature to mature seeds of buckwheat [19]. In addition, increase in the amount of sucrose and rutin was also reported during seed maturation of Fagopyrum species [15,20]. Molecular dissection of the genetic machinery contributing to nutritional differences in the seeds of $F$. tataricum, in particular the rice-tartary type over F. esculentum (common buckwheat) was undertaken 
through cDNA-AFLP since it is an open architecture technology for global transcriptional analysis in a non-model plant species $[21,22]$.

Large numbers of TDFs with differential expression pattern were observed in different seed developmental stages of both the Fagopyrum species. TDFs with differential expression patterns belonged to genes involved in primary and secondary metabolism, transportation, signal transduction, gene regulation, photosynthesis \& energy, defense and cellular processes in seed developmental stages of the Fagopyrum spp.; Additional file 1: Table S1. Out of 167 differential TDFs, only 22 showed $50-70 \%$ identity with the available floral transcriptome of both the Fagopyrum species [12], thereby, suggesting that most of the TDFs identified in the current study represented new genes. TDFs involved in transport, transcription, secondary metabolism, amino acid \& protein metabolism, carbohydrate metabolism and photosynthesis were relatively higher in number and expression pattern in rice-tartary over common buckwheat. Higher expression of TDFs involved in secondary metabolism and transportation such as chalcone synthase, dihydroflavonol reductase, UDP glucosyl transferases, $A B C$ transporters, MATE efflux carrier proteins, which are known to be involved in biosynthesis, accumulation and transportation of flavonoids, indicate their involvement in significantly higher flavonoid content in rice-tartary buckwheat $[14,16,23]$. Increased transcript abundance of TDF encoding Lys/His transporter in ricetartary buckwheat was implicated for higher amount of histidine in this species [24]. TDFs involved in amino acid \& protein metabolism (like Ub protein ligases, alanine glyoxylate amino transferases, cystein proteases), transcriptional regulation (MYB 118, MYB 112, GAMYB, histone acetyl transferases) and signal transduction (calmodulin binding protein, protein kinases, PEP carboxylase) were also found to be abundant in rice-tartary buckwheat. Most of these TDFs represent genes with their direct or indirect role in controlling the growth and development of seeds and/or their nutritional composition. On the basis of differential expression pattern of transcripts in rice-tartary and common buckwheat, the TDFs representing genes which have been implicated in biosynthesis, modification, regulation and transport of secondary metabolites $[16,18,23]$ were chosen to investigate their role, through qRT-PCR analysis, in the biosynthesis of higher rutin content in the seeds of rice-tartary over common buckwheat.

The flavonoid content increase in buckwheat seedlings has been attributed to the increase in the concentration of sucrose [25]. In addition, sugars also act as developmental signals regulating seed maturation and accumulation of flavonoids in plants such as Arabidopsis, $V$. vinifera [26-28]. Exponential increase in the transcript of a sugar transporter (JN982735) from flowers (S6) to immature seeds (S7) of rice-tartary compared to common buckwheat suggests its contribution in higher content of flavonoids and fagopyritols in the seeds of ricetartary buckwheat. Relatively increased transcript abundance of auxin efflux carrier protein (JN982731) in different seed maturation stages (S8 \& S9) of F. esculentum suggests its negative role in the biosynthesis of flavonoids, which are present in lower amounts in different growth stages of $F$. esculentum [15]. Flavonoids have been implicated as inhibitors of auxin transport in Arabidopsis $[18,29]$. The ABC and MATE classes of transporters are known to be involved in the transport of flavonoids from cytosol into vacuoles $[16,23,30]$. In present study the abundance of TDF $\mathrm{ABC}$ transporter (JN982732) was relatively higher in flowering to seed maturation stages, S6 (4.7x), S7 (95.4x), and S8 (2.4x) of ricetartary buckwheat compared to common buckwheat suggested that this gene might be playing a key role in the transport of flavonoids (rutin, quercetin and quercitrin) in rice-tartary buckwheat. Also, it has been shown that biosynthesis of flavonoids takes place in lower parts of Fagopyrum spp. and then gets transported to upper parts [13].

Significantly higher expression of 4 TDFs representing genes for ubiquitin protein ligase, $\mathrm{ABC}$ transporter, sugar transporter and calmodulin binding protein in $\mathrm{S} 7$ of ricetartary buckwheat compared to $F$. esculentum suggests their major involvement in nutritional superiority of ricetartary buckwheat. The calmodulin binding proteins regulate diverse cellular processes by interacting with other proteins and help in secondary metabolism by acting as secondary messengers through signal transduction $[31,32]$. In addition, calmodulin proteins are also known to induce anthocyanin biosynthesis in $V$. vinifera [33]. Extensins, the major structural proteins in plant cell wall play important role in various biological processes such as embryo development, root hair growth, seed coat development, defense, etc. [34,35]. Increased transcript abundance of extensin protein (JQ003863) in mature seeds of rice-tartary buckwheat in comparison to common buckwheat may contribute to development of seeds of both the Fagopyrum species.

Transcription factors are known to play important role in various seed development processes and regulation of secondary metabolism [36-38]. Zn finger binding proteins (JN982723) have been implicated in regulation of important biological processes such as flower and seed development, seed germination, stress tolerance in Arabidopsis [39,40]. Expression of a TDF representing a gene for $\mathrm{Zn}$ finger binding protein was relatively higher in seed developing stages S8 and S9 of common buckwheat compared to ricetartary buckwheat. Transcript of a TDF encoding for another transcription factor MYB 118 (JN982734) was high in the flowers (S6) of rice-tartary compared to common buckwheat. 
Ub protein ligases (JN982742) are known to regulate various biological processes like photomorphogenesis, hormonal response, senescence, floral, embryo and seedling development through degradation of proteins as well as regulates phenylpropanoid pathway during UV stress and sugar signaling during seedling development [41-43]. Relatively higher expression of Ub protein ligase in immature seeds (S7) of rice-tartary buckwheat has been observed in the present study. Significantly higher expression of most of the selected TDFs during early seed formation stage (S7) of rice-tartary buckwheat (Figure 6E) reflects their biological importance in maintaining higher amounts of rutin, which otherwise drops significantly in the same stage of F. esculentum.

\section{Conclusions}

The present study concludes that in addition to structural genes, the other classes of genes such as regulators, modifiers and transporters are equally important in contributing to higher flavonoids content and nutritional superiority of $F$. tataricum (rice-tartary buckwheat) over $F$. esculentum. Increased transcript abundance of selected TDFs in rice-tartary buckwheat during early seed maturation stage (S7) i.e. the transition from flowers to seed formation also reflects their contribution not only in higher rutin content but also in other biological processes which are contributing to overall nutritional differences between both the Fagopyrum species. In summary, the cDNA-AFLP technology was successfully utilized to identify genes that are differentially expressed in seed maturation stages of two Fagopyrum spp. Therefore, identification of several genes representing regulators, modifiers or transporters, has opened up avenues to investigate their precise role in contributing to higher rutin content as well as overall nutritional superiority of rice-tartary over common buckwheat.

\section{Methods}

\section{Plant material}

Seeds of F. tataricum (rice-tartary buckwheat) and $F$. esculentum (common buckwheat) were procured from the National Bureau of Plant Genetic Resources (NBPGR), Regional Research Station, Phagli, Shimla (H.P. India), India and germinated in a potting mixture consisting of soil and vermiculite in a ratio of 1:1. Seedlings were grown under controlled conditions of light (intensity 300-1400 lx), temperature $\left(25 \pm 2^{\circ} \mathrm{C}\right)$, humidity $(\approx 70 \%)$, and photoperiod of $14 \mathrm{~h}$ day/10 h night. Samples of different seed developmental stages i.e. from flowering to seed maturation (Figure 1) were collected (June to September). Samples were harvested between 9 and $10 \mathrm{AM}$, immediately frozen in liquid nitrogen and stored at $-80^{\circ} \mathrm{C}$ for further use in isolation of genomic DNA and mRNA.

\section{Isolation of genomic DNA, RNA and CDNA synthesis}

Genomic DNA was isolated from leaf samples of both the Fagopyrum spp. by following the protocol of Murray and Thompsan [44]. Total RNA was isolated from flowers, immature seeds and mature seeds of both the Fagopyrum spp. by using Raflex RNA isolation kit $\left(\mathrm{GeNei}^{\mathrm{TM}}\right.$, Bangalore, India) by following manufacturer's instructions. Quality of DNA and RNA was checked by $1 \%(w / v)$ ethidium bromide-stained agarose gel and from the absorbance spectrum at wavelengths $260 \mathrm{~nm}$ and $280 \mathrm{~nm}$.

First strand cDNA was synthesized from $5 \mu \mathrm{g}$ of RNAfree from DNA (RNA preparation was treated with $2 \mathrm{U}$ of DNAse I), reverse transcribed by using M-MuLV reverse transcriptase $\left(\mathrm{GeNei}^{\mathrm{TM}}\right)$ and an oligo-dT (12-18) primer. Double-stranded cDNA was synthesized according to a standard double-stranded cDNA synthesis protocol [45], using DNA polymerase I (Escherichia coli) and T4 DNA ligase (New England Biolabs Inc., Beverly, MA).

\section{cDNA-AFLP analysis}

About 500 ng of double stranded cDNA was subjected to standard AFLP template production according to Vos et al. [46]. cDNA was digested with restriction enzymes MseI and Pst (NEB, England). Digested products were then ligated to adapters with sequences as follows: $M s e I$ adapter, 5'-GACGATGAGTCCTGAG-3', 3'-TACTCAGGACTCAT5'; PstI adaptors 5'CTCGTAGGACTGCGTACATGCA-3', 3'-TGTACGCAGTCTAC-5'. Adapter-ligated DNA served as a template for pre-amplification, with PCR parameters of 30 cycles of $30 \mathrm{~s}$ at $94^{\circ} \mathrm{C}, 60 \mathrm{~s}$ at $56^{\circ} \mathrm{C}$, and $60 \mathrm{~s}$ at $72^{\circ} \mathrm{C}$. The diluted (30-fold) amplified products were used as the template for selective amplification. Equal amounts of preamplified products were amplified with primers having selective nucleotides at the 3' end in a total volume of $20 \mu \mathrm{l}$; Additional file 2: Table S2. First selective amplification cycle consisted of $30 \mathrm{~s}$ at $94^{\circ} \mathrm{C}, 30 \mathrm{~s}$ at $65^{\circ} \mathrm{C}$, and $60 \mathrm{~s}$ at $72^{\circ} \mathrm{C}$; annealing temperature was lowered by $0.7^{\circ} \mathrm{C}$ per cycle during the next 12 cycles, followed by 23 cycles at $94^{\circ} \mathrm{C}$ for $30 \mathrm{~s}, 56^{\circ} \mathrm{C}$ for $30 \mathrm{~s}$, and $72^{\circ} \mathrm{C}$ for $60 \mathrm{~s}$. All PCR reactions were carried out in Applied Biosystem model no-9902 Veriti thermal cycler. To each PCR product $7.5 \mu \mathrm{l}$ of formamide dye (98\% formamide, $10 \mathrm{mM}$ EDTA, 0.005\% xylene cyanol FF, and $0.005 \%$ bromophenol blue) was added, and $7 \mu$ l of each sample was loaded onto a pre-warmed $6 \%$ polyacrylamide gel using $1 \mathrm{X}$ Tris-borate-EDTA (TBE) buffer. Electrophoresis was then run for $2.5 \mathrm{~h}$ at $65 \mathrm{~W}$ and the gels were silver stained using a silver staining kit (Promega cat. \#Q4132, Madison, WI), following the manufacturer's instructions.

\section{Transcript-derived fragment (TDF) isolation and re-amplification}

Differentially expressed TDFs based on presence, absence or differences in intensity were cut with a sharp 
blade from the gel with care to avoid any contaminating fragment(s), eluted in $50 \mu \mathrm{l}$ of sterile double distilled water, incubated at $95^{\circ} \mathrm{C}$ for $15 \mathrm{~min}$ and then hydrated overnight at $4^{\circ} \mathrm{C}$. An aliquot of $2 \mu \mathrm{l}$ was used for reamplification in a total volume of $25 \mu \mathrm{l}$, using the same set of corresponding selective primers and PCR conditions as used for the selective amplification, except that an annealing temperature of $56^{\circ} \mathrm{C}$ for 35 cycles was used. PCR products were resolved in a $2 \%$ agarose gel; each single band was isolated and eluted using the Genaxy DNA gel extraction kit (Genaxy Biosciences Inc., USA). The reproducibility of cDNA AFLP was verified by repeating the experiment twice.

\section{Cloning and sequencing of TDFs}

Eluted TDFs were cloned into the plasmid pGEM-Teasy ${ }^{\circledR}$ vector (Promega Corp., Madison, WI) following the manufacturer's protocol and then sequenced. Sequences of TDF (with vector sequences trimmed off, where plasmid was used as the template) were then analyzed for their homology against the publicly available non-redundant genes/ ESTs/Transcripts in the database (http://www.ncbi.nlm. nih.gov/BLAST, http://www.arabidopsis.org/Blast) using BLASTN and BLASTX algorithms. TDFs were also checked for putative function against Arabidopsis database using FASTA tool (http://www.arabidopsis.org/cgi-bin/ fasta/nph-TAIRfasta.pl) developed by TAIR, [47].

\section{Real-time RT-PCR analysis}

Specific primer pairs were designed for TDFs; Additional file 3: Table S3 and tested by real time RTPCR. Primers specific for buckwheat $26 \mathrm{~S} r R N A$ and Histone $\mathrm{H} 3$ were used for the normalization of reactions. Real-time PCR reactions were performed in duplicate on a CFX 96 system (Bio-Rad Laboratories; Hercules,CA) with the iScript one step RT PCR Kit (Bio-rad). PCR protocol was as follows: denaturation for $5 \mathrm{~min}$ at $94^{\circ} \mathrm{C}$, followed by 40 cycles each of denaturation for $20 \mathrm{~s}$ at $94^{\circ} \mathrm{C}$, annealing for $30 \mathrm{~s}$ at $55-61^{\circ} \mathrm{C}$, and one elongation step for $20 \mathrm{~s}$ at $72^{\circ} \mathrm{C}$. Significance of differences between treatments was statistically analyzed. Whisker plots were drawn for qRT-PCR data to determine folds expression of TDFs in F. tataricum compared to F. esculentum by using MINITAB-14.

\section{Additional files}

Additional file 1: Table S1. Sequence homology: Functional characterization of transcript derived fragments (TDFs) based on BLAST X and TAIR FASTA analysis.

Additional file 2: Table S2. Primers List: Primers used for CDNA-AFLP analysis.

Additional file 3: Table S3. Primers List: Primers used for real time qRT-PCR analysis.

\section{Competing interests}

The authors declare no competing interests.

\section{Authors' contributions}

NG carried out the experiments, analyzed the data and drafted the manuscript. PKN participated in data analysis. RSC proposed and supervised the research, helped to draft and reviewing the manuscript. All authors read and approved the final manuscript.

\section{Acknowledgements}

The authors are thankful to the Department of Biotechnology, Ministry of Science \& Technology, Govt. of India for providing research grant to RSC.

Received: 24 January 2012 Accepted: 29 May 2012

Published: 12 June 2012

\section{References}

1. Campbell CG: Buckwheat. Fagopyrum esculentum Moench. Promoting the conservation and use of underutilized and Neglected Crops (Vol 19), IPK, Germany and IPGRI. Rome, Italy: Germany and IPGRI; 1997.

2. La Casa C, Villegas I, Alarcón de la Lastra C, Motilva V, Martín Calero MJ: Evidence for protective and antioxidant properties of rutin, a natural flavones, against ethanol induced gastric lesions. J Ethnopharmacol 2000, 71:45-53.

3. Landberg R, Sun Q, Rimm EB, Cassidy A, Scalbert A, Mantzoros CS, Hu FB, van Dam RM: Selected dietary flavonoids are associated with markers of inflammation and endothelial dysfunction in U.S. women. J Nutr 2011, 141(4):618-625.

4. Arora RK, Engels JMM: Buckwheat genetic resources in the Himalayan region: Present status and future thrust. Rome: IPGRI; 1992:87-91.

5. Chauhan RS, Gupta N, Sharma SK, Rana JC, Sharma TR, Jana S: Genetic and genome resources in Buckwheat- Present and Future Perspectives. Eur J Plant Sci Biotech 2010, 4(1):33-34.

6. Shao JR, Zhou ML, Zhu XM, Wang DZ, Bai DQ: Fagopyrum wenchuanense and Fagopyrum qiangcai, two new species of Polygonaceae from Sichuan, China. Novon 2011, 21(2):256-261.

7. Li SQ, Zhang QH: Advances in the development of functional foods from buckwheat. Crit Rev Food Sci Nutr 2001, 41:451-464.

8. Fabjan N, Rode J, Kosir IJ, Wang Z, Zhang Z, Kreft I: Tartary buckwheat (Fagopyrum tataricum Gaertn.) as a source of dietary rutin and quercitrin. J Agric Food Chem 2003, 51:6452-6455.

9. Steadman KJ, Burgoon MS, Schuster RL, Lewis BA, Edwardson SE, Obendorf RL: Fagopyritols, D-chiro-inositol, and other soluble carbohydrates in buckwheat seed milling fractions. J Agric Food Chem 2000, 48(7):2843-2847.

10. Bonafaccia G, Marocchini M, Kreft I: Composition and technological properties of the flour and bran from common and tartary buckwheat. Food Chem 2003, 80:9-15.

11. Wang Y, Campbell CG: Tartary buckwheat breeding (Fagopyrum tataricum L. Gaertn.) through hybridization with its Rice-Tartary type. Euphytica 2007, 156:399-405.

12. Logacheva D, Kasianov AS, Vinogradov DV, Samigullin TH, Gelfand MS, Makeev VJ, Penin AA: De novo sequencing and characterization of floral transcriptome in two species of buckwheat (Fagopyrum). BMC Genomics 2011, 12:30

13. Li X, Park NI, Xu H, Woo S-H, Park CH, Park SU: Differential expression of flavonoid biosynthesis genes and accumulation of phenolic compounds in common buckwheat (Fagopyrum esculentum). J Agric Food Chem 2010, 58(23):12176-12181.

14. Park NI, Li X, Suzuki T, Kim SJ, Woo SH, Park CH, Park SU: Differential Expression of Anthocyanin Biosynthetic Genes and Anthocyanin Accumulation in Tartary Buckwheat Cultivars 'Hokkai T8' and 'Hokkai T10'. J Agric Food Chem 2011, 56(6):2356-2361.

15. Gupta N, Sharma S, Rana JC, Chauhan RS: Expression of flavonoid biosynthesis genes vis-à-vis rutin content variation in different growth stages of Fagopyrum species. J Plant Physiol 2011, 168(17):2117-2123.

16. Grotewold E (Ed): The Science of Flavonoids. Volume VIII.: Springer press; 2006.

17. Bovy A, Schijlen E, Hall RD: Metabolic engineering of flavonoids in tomato (Solanum lycopersicum): the potential for metabolomics. Metabol 2007, 3:399-412. 
18. Hichri I, Barrieu F, Bogs J, Kappel C, Delrot S, Lauvergeat V: Recent advances in the transcriptional regulation of the flavonoid biosynthetic pathway. J Exp Bot 2011, 62(8):2465-2483.

19. Obendorf RL: Buckwheat Fagopyritols. Advances in buckwheat research. 7th Intl Symp Buckwheat 1998, 3:65-71.

20. Horbowicz M, Brenac P, Obendorf RL: Fagopyritol B1, O-a-Dgalactopyranosyl-(1 $\rightarrow$ 2)-D-chiro-inositol, a galactosyl cyclitol in maturing buckwheat seeds associated with desiccation tolerance. Planta 1998, 205:1-11.

21. Bachem CW, van der Hoeven RS, de Bruijn SM, Vreugdenhil D, Zabeau M, Visser RG: Visualization of differential gene expression using a novel method of RNA fingerprinting based on AFLP: analysis of gene expression during potato tuber development. Plant J 1996, 9:745-753.

22. Meyers BC, Galbraith DW, Nelson T, Agrawal V: Methods for transcriptional profiling in plants. Be fruitful and replicate. Plant Physiol 2004, 135:637-652.

23. Zhao J, Huhman D, Shadle G, He XZ, Sumner LW, Tang Y, Dixon RA: MATE2 mediates vacuolar sequestration of flavonoid glycosides and glycoside malonates in Medicago truncatula. Plant Cell 2011, 23:1536-1555.

24. Kusano T, Nakayama N, Doi J, Kiyomasa Y, Chine H, Ikeda K: Studies on nutritional aspects of tartary buckwheat. In Proc. $5^{\text {th }}$ Intl. Symp. Buckwheat:; :453-454. August 20-26 1992, Taiyuan, China.

25. Li X, Park NI, Park CH, Kim SG, Lee SY, Park SU: Influence of sucrose on rutin content and flavonoid biosynthetic gene expression in seedlings of common buckwheat (Fagopyrum esculentum Moench). Plant omics $J$ 2011, 4(4):215-219.

26. Wobus $\mathrm{U}$, Weber $\mathrm{H}$ : Sugars as signal molecules in plant seed development. Biol Chem 1990, 380(7-8):937-944.

27. Solfanelli C, Poggi A, Loreti E, Alpi A, Perata P: Sucrose-specific induction of the anthocyanin biosynthetic pathway in Arabidopsis. Plant Physiol 2006, 140(2):637-646.

28. Ferri M, Righetti $L$, Tassoni A: Increasing sucrose concentrations promote phenylpropanoid biosynthesis in grapevine cell cultures. J Plant Physiol 2011, 168:189-195

29. Brown DE, Rashotte AM, Murphy AS, Normanly J, Tague BW, Peer WA, Taiz L, Muday GK: Flavonoids act as negative regulators of auxin transport in vivo in Arabidopsis. Plant Physiol 2001, 126:524-535.

30. Buer CS, Muday GK, Djordjevic MA: Flavonoids Are Differentially Taken Up and Transported Long Distances in Arabidopsis. Plant Physiol 2007, 145:478-490.

31. Zielinski RE: Calmodulin and calmodulin-binding proteins in plants. Ann Rev Plant Physiol Plant Mol Biol 1998, 49:697-725

32. Luan S, Kudla J, Rodriguez-Concepcion M, Yalovsky S, Gruissem W: Calmodulins and calcineurin B-like proteins: calcium sensors for specific signal response coupling in plants. Plant Cell 2002, 14:S389-S400.

33. Vitrac X, Larronde F, Krisa S, Decendit A, Deffieux G, Mérillon JM: Sugar sensing and $\mathrm{Ca} 2+-$ calmodulin requirement in Vitis vinifera cells producing anthocyanins. Phytochem 2000, 53(6):659-665.

34. Lianhua $G$, Tongming $Y$, Suxian $L$, Minern H, Mingxiu W: A review of extensins in plant cell wall. Scientia Silvae Sinicae 2010, 12:144-152.

35. Xu C, Takáč T, Burbach C, Menzel D, Samaj J: Developmental localization andthe role of hydroxyproline rich glycoproteins during somatic embryogenesis ofbanana (Musa spp. AAA). BMC Plant Biol 2011, 24:11-38.

36. Karin M: Too many transcription factors: positive and negative interactions. New Biol 1990, 2:126-13.

37. Fujimoto SY, Ohta M, Usui A, Shinshi H, Ohme-Takagi M: Arabidopsis ethylene-responsive element binding factors act as transcriptional activators or repressors of GCC box-mediated gene expression. Plant Cell 2000, 12(3):393-404

38. Agarwal P, Kapoor S, Tyagi AK: Transcription factors regulating the progression of monocot and dicot seed development. Bioessay 2011, 33:189-202

39. Papi M, Sabatini S, Bouchez D, Camilleri C, Costantino P, Vittorioso P: Identification and disruption of an Arabidopsis zinc finger gene controlling seed germination. Genes Dev 2000, 14:28-33.

40. Xu R, Li QQ: A RING-H2 zinc-finger protein gene RIE1 is essential for seed development in Arabidopsis. Plant Mol Biol 2003, 53:37-50.

41. Endt DV, Kijne JW, Memelink J: Transcription factors controlling plant secondary metabolism: what regulates the regulators? Phytochem 2002, 61:107-114.
42. Peng $\mathrm{RH}$, Yao O-H, Xiong AS, Fan HO, Li X, Peng YL: Ubiquitin-conjugating enzyme (E2) confers rice UV protection through phenylalanine ammonia lyase gene promoter unit. Acta Bot $\operatorname{Sin} 2003,45(11): 1351-1358$.

43. Huang JY, Jie ZJ, Wang LJ, Yan XH, Wei WH: Analysis of the differential expression of the genes related to Brassica napus seed development. Mol Biol Rep 2011, 38:1055-1061.

44. Murray MG, Thompson WF: Rapid isolation of high molecular weight plant DNA. Nucl Acid Res 1980, 8(19):4321-4325.

45. Sambrook J, Russell D: Molecular Cloning: A Laboratory Manual (3rd ed.). Cold Spring Harbor Laboratory 2001, 1,2 \&3.

46. Vos P, Hogers R, Bleeker M, Reijans M, van de Lee T, Hornes M, Frijters A, Pot J, Peleman J, Kuiper M: AFLP: a new technique for DNA fingerprinting. Nucl Acid Res 1995, 23:4407-4414.

47. Rhee SY, Beavis W, Berardini TZ, Chen G, Dixon D, Doyle A, et al: The Arabidopsis Information Resource (TAIR): a model organism database providing a centralized, curated gateway to Arabidopsis biology, research materials and community. Nucl Acids Res 2003, 31:224-228.

doi:10.1186/1471-2164-13-231

Cite this article as: Gupta et al:: Differential transcript profiling through CDNA-AFLP showed complexity of rutin biosynthesis and accumulation in seeds of a nutraceutical food crop (Fagopyrum spp.). BMC Genomics 2012 $13: 231$.

\section{Submit your next manuscript to BioMed Central and take full advantage of:}

- Convenient online submission

- Thorough peer review

- No space constraints or color figure charges

- Immediate publication on acceptance

- Inclusion in PubMed, CAS, Scopus and Google Scholar

- Research which is freely available for redistribution 